\title{
A HISTÓRIA REVERSA EM EL PAÍS DE TOÓ DE RODRIGO REY ROSA
}

\author{
Luciana Arruda Alves Santana ${ }^{1}$
}

RESUMO: Este artigo busca propor uma leitura alegórica e, por isso mesmo, hermenêutica da obra de Rodrigo Rey Rosa, El país de Toó, publicada pela editora Alfaguara em 2018 com base no pensamento benjaminiano barroco e, também, atual, sobre a discussão proposta no livro a Origem do Drama Trágico Alemão no que concerne a relação entre história e alegoria. Lemos este texto de Rey Rosa a partir da construção do pensamento de Benjamin em que o passado e o presente político são inerentes tornando-se, desse modo, impossível falar de um sem o outro. Os gestos de leitura implicados em El país de Toó comprovam essa relação e representa a atualidade do presente como história reversa daquilo que não foi tomado pelo gesto político contemporâneo como "merecedor" de ser revisto e, por isso mesmo, pensado como reflexo de uma história viva.

Palavras-chaves: História. Presente. Alegoria. Guatemala.

ABSTRACT: This article seeks to propose an allegorical and, therefore, hermeneutic reading of the work by Rodrigo Rey Rosa, El País de Toó, published by the Alfaguara publishing house in 2018 based on Benjamin Baroque thought and also current on the discussion proposed in the book The Origin of German Tragic Drama regarding the relationship between history and allegory. We read this text by Rey Rosa from the construction of Benjamin's thought in which the political past and present are inherent, thus making it impossible to speak of one without the other. The reading gestures involved in $E l$ País de Toó prove this relationship and represent the present day as a reverse history of what

\footnotetext{
${ }^{\text {I }}$ Mestre e doutora em Literatura pela Universidade de Brasília-UnB. Suas maiores especialidades e campo de estudo estão concentradas no estudo do romance e da literatura contemporânea latino-americana assim como o da teoria literária. E-mail: lucianaarru@gmail.com.
} 
was not taken by the contemporary political gesture as "deserving" to be reviewed and, for this very reason, thought of as a reflection of a history alive.

Keys-words: History. Present. Allegory. Guatemala.

\section{INTRODUÇÃO}

Em 2004, o romancista guatemalteco Rodrigo Rey Rosa publicou uma crônica na Revista Granta intitulada El Tesoro en la Sierra², que relatava a destruição de comunidades em Huehuetenango, Guatemala; uma devastação que resultou de práticas de exploração de ouro por corporações internacionais de mineração. A partir de então, Rey Rosa vai explorar em seu romance El país de Toó, publicado em 2018, questões políticas contemporâneas ainda vivenciadas na realidade social da Guatemala, das quais a indústria mineradora ainda perpassa suas discussões no romance, evidenciando problemas que, via de regra, poderiam ter sido superadas depois de tantas mortes - civis, indígenas e camponeses - ao longo de tantas décadas mas que, ao contrário, ainda repercutem como fantasmas que assombram o presente atual da Guatemala.

Assim como na história literária dos demais países da América Latina, o romance político latino-americano surge em maior medida naqueles países em que um autor, comprometido com uma determinada situação social, sente a necessidade de denunciar injustiças, arbitrariedades ou abusos de autoridade. Faz isso para dois propósitos principais: primeiro, para que os cidadãos estejam cientes da realidade e a gerenciem - talvez - unindose para superá-la, para mudarem a realidade deles mesmos por serem sempre os mais impactados e prejudicados; e, segundo, para tornar essa realidade conhecida além das fronteiras em si e para que outros saibam o que está por trás das máquinas institucionais. Às vezes, para mostrar como as forças estrangeiras agem interferindo na política ou na economia doméstica; outras, esta literatura pode refletir a manipulação, a chantagem ou violência das autoridades. Embora nenhuma área do planeta viva fora de problemas e confrontos, na América Latina - mais ainda, poderíamos dizer, na América Central - esses

\footnotetext{
${ }^{2}$ Disponível integralmente em https://www.granta.com.es/2018/1o/el-tersoro-de-la-sierra/
} 
romances têm um terreno especial de reprodução e se destacam por sua regularidade no meio intelectual latino. Não foi diferente na Guatemala.

No caso de Rey Rosa em El país de Toó, há duas coisas importantes que podemos destacar para analisá-lo a partir da alegorese benjaminiana e entendê-lo como forma artística da novela contemporânea. A primeira delas é alegoria barroca representada no texto a partir de elementos ou fragmentos literários trazidos pelos próprios personagens. O que se percebe na leitura desse texto é uma estratégia de marcação do espaço-tempo narrativo a partir desses elementos que são recortados de dentro da narrativa para desenvolver outras questões pertinentes no discurso romanesco e que acabarão por aparecer mais explicitamente no decorrer do narrado.

Há uma demarcação interessante no texto de Rey Rosa entre o tempo presente (profano/político) e o tempo passado (sagrado) - como história da Guatemala - que não são descartados nos acontecimentos para privilegiar um foco narrativo apenas em detrimento de tantos outros que aparecem nesse mosaico. O Huilpil “de Toó”, traje típico da cultura Totonicapán que ainda hoje segue as linhas de tradições dos antigos povos indígenas da região, aparece em diferente momentos da narrativa como uma espécie de divisor de águas para entender parte da discussão proposta pelo romance: De um lado, o Huipil $^{3}$ traz a representação alegórica da origem de tudo e daquilo que está guardado como sagrado de um povo, o que representa as raízes desse mesmo povo e seus antepassados; aquilo que deveria existir e persistir como realidade para as diferentes etnias culturais presentes na Guatemala - pensando aí na luta do povo maia em conservar sua cultura diante da colonização espanhola até a resistência ainda hoje presente na luta por suas terras e seu povo. De outro a narrativa opõe e apaga - assim como a realidade política faz acontecer

\footnotetext{
${ }^{3}$ Huipil, é uma palavra que vem da língua Nahuatl, uma das línguas nativas do México. Se pronuncia huipilli, significa blusa ou vestido adornado, parte dos trajes típicos guatemaltecos por excelência, usados em todos os departamentos com algumas diferenças. Seu uso é considerado uma das mais antigas tradições entre as mulheres indígenas e sua origem remonta aos tempos pré-hispânicos, mantendo sua elaboração, decoração e uso como era feito na época, até os dias de hoje. Os temas bordados nos huipiles podem ter conceitos geométricos que representam figuras humanas, animais ou vegetais, cada elemento tendo um significado simbólico para cada indígena que dele faz uso. O huipil pode ser usado no dia a dia, embora em ocasiões especiais seja usado um diferente, mais ornamentado e com mais cores. O que a mulher usar no dia do casamento será o mesmo que ela deve usar no dia da sua morte, seguindo a tradição dos tempos pré-hispânicos.
} 
empiricamente - todo esse quadro sacralizado pelo Huipil denunciando o massacre a este sagrado, o profano representado pela exploração desse mesmo povo numa espécie de flagelo incontrolável e perene desde a década de 1970; evidencia o que a história sempre disse e reitera a cada ato destrutivo de um país pelo capital desenfreado que fere e massacra a origem, o passado, as raízes, razão de ser de um povo.

Quem movimenta esse divisor de águas na narrativa de El país de Toó é a personagem Dona Matilde e, em algumas cenas, Goya, sua sobrinha. Há um mundo diferente em Toó sacralizado pelo Huipil que essas personagens trazem com elas e que sempre é posto em destaque pelo narrador do texto de Rey Rosa. O traje de Toó - sendo Toó uma pequena república guatemalteca ficcionalizada no espaço narrativo do texto - aparece sempre como traje sagrado ou apenas de uso dos anciões da comunidade indígena ao sul de Ixil ${ }^{4}$ onde esse espaço sagrado é localizado na narrativa também não por acaso. Aparece no texto com a ideia de uma espécie voz no texto que não deixa morrer a origem. Um objeto fundador da alegoria de Benjamim que resgata a história para penteá-la à contrapelo trazendo à tona a resistência de um povo contra a ascensão do imperialismo americano (e nos últimos anos do Chinês tambéms) e seu controle governamental sobre a exploração da Guatemala

\footnotetext{
${ }^{4}$ Geograficamente, o país Ixil incorpora os municípios de Chajul, Nebaj e San Juan Cotzal - três municípios predominantemente maias nas cordilheiras orientais do planalto de Cuchumatán. Um aumento dramático da população como o que ocorreu durante os 30 anos, de 1950 a 1980 , sobrecarregaria os recursos e testaria a determinação política de qualquer sociedade. Em uma sociedade fundamentalmente dividida e desigual como a Guatemala, onde a maior parte do crescimento populacional pós-1950 ocorreu entre os pobres rurais, muitos deles índios maias, as pressões exercidas sobre a terra, disponibilidade de alimentos, oportunidades de emprego, saúde e educação, e outras necessidades básicas atingiram níveis de crise. Foi nessas circunstâncias que, durante a década de 1970, o Exército Guerrilheiro dos Pobres (EGP) começou a se infiltrar nas comunidades maias nas terras altas de Cuchumatàn, entre elas as do país Ixil (Payeras 1983). A perspectiva, mais percebida do que real, de uma massa de índios se rebelando para travar a luta armada revolucionária contra um governo incapaz ou não querendo criar uma sociedade mais justa desencadeou em toda a Guatemala uma contra-insurgência brutal (Carmack, 1988). No país Ixil, as consequências da contra-insurgência foram inúmeras e profundas, em nenhum lugar mais claramente reveladas do que nas estatísticas da população registrada e projetada para a década entre 1980 e 1990. A resiliência maia, uma característica notável dos tempos coloniais (Lovell 1988), está hoje em evidência em todo o país ixil. Problemas assustadores permanecem - a presença conspícua dos militares, divisões dentro das comunidades devido ao culto religioso, serviço continuado em Patrulhas Civis, muito pouca terra para uma população que começa a crescer rapidamente novamente - mas, a década mais sombria no país Ixil terminou quando os índios maias assumiram a importância passos para ajudar a moldar seu próprio futuro. Tradução nossa.
}

${ }_{5}^{5}$ As exportações guatemaltecas sofreram mudanças estruturais muito significativas na última década. Vale ressaltar, por um lado, que os principais destinos das exportações guatemaltecas mudaram: com a entrada em vigor do DR-CAFTA desde janeiro de 2005, a participação dos Estados Unidos nas exportações guatemaltecas 
especificamente nas terras ocupadas ainda por muitos indígenas e camponeses. Algumas cenas do texto nos mostram com maior clareza esses aspectos que colocamos inicialmente aqui para, posteriormente, contratá-los com o presente ficcional em oposição a essa origem:

La nana [Dona Matilde], que dormía en el camarote inferior, le oyó moverse y se levantó para ayudarle a bajar. Lo acompañó al baño, y luego le dio su desayuno de cereal con leche en la cocina, en la mesita baja que solo usaba él. Jacobo acomodó al delfín, del tamaño de um bebé, en la sillita a su lado, y la mujer se puso a lavar los platos de la fiesta de Año Nuevo, que no había terminado hasta el amanecer. Mientras fregaba, se quejaba del calor, pero vestía, como siempre, su traje de Toó: corte, faja y huipil. La cara y el cuello le sudaban profusamente. (REY ROSA, 2018:20)

La sobrina estaba en una gasolinera Puma pasando él Trébol, dijo nana.

Igual que Dona Matilde, vestia um traje de Toó; pero calzaba tênis em vez de sandálias. Era pequeña y delgada y El Cobra la encontró muy atractiva. Se llamaba Gregória y le decían Goya. Un amigo la acompañaba. Lo presentó: un artista del lago de Atitlán. (REY ROSA, 2018:20)

Fue para su cumpleaños número nuevo, el domingo 26 de junio del año 2011 , cuando Jacobo retomó el hilo de su vida verbal. El prolongado letargo de su actividad lingüística terminó gracias a un acto de curandería ejecutado por Dona Matilde, la nana [...]. Esta vez lhe llevaba para darle, además de las tortillas de maís y unos tamalitos dulces, un hongo seco color carne del tamaño de una hostia. [...] Pocos son quienes conocen sus calidades curativas o sus poderes mágicos, incluso en Toó, donde el común de ça gente lo cree venenoso y evita su contacto. (Kakulhá, "trueno y relámpago", lo llaman, o ixtantlalok.) [...] iHabía recuperado el habla! Por puro milagro, dijeron los doctores. [...] Aprendió a contar en maya y a decir los nombres de los días. Leyeron juntos, en quiché y en español, varios pasajes del Popol Vuh, el Libro del Consejo, cuyo capítulo segundo se convirtió en lalectura favorita de Jacobo. (REY ROSA, 2018:174)

Em oposição a essa origem, à cultura maya e à história de sofrimento e resistência do povo indígena da Guatemala, o texto segue coberto de outras referências e personagens que mostram ao leitor perspectivas outras da realidade contemporânea do país. A figura central no desafio do status quo da atualidade em oposição à toda origem que Dona Matilde

aumentou significativamente 29, passando de 29,38\% em 2004 para 50,09\% em 2005-, mas desde então caiu para níveis históricos próximos a $40 \%$ durante 2007-2012. Da mesma forma, a América Central diminuiu sua participação nas exportações da Guatemala, mas continua a ser um mercado altamente relevante: de níveis acima de $40 \%$ desde o final da década de 1990 para menos de 30\% desde 2009. "China total" -China, Hong Kong e Macau -, com a maior taxa média de crescimento anual (TCPA) entre os principais destinos das exportações $-45,3 \%$ durante $1993-2000$ e 40,1\% durante 200I-2012, e das exportações totais, 10,6\% e 13,9\%, respectivamente- tornou-se os vinte -nono destino mais importante na Guatemala; As exportações da Guatemala para a "China total" ainda não ultrapassam o,4\% das exportações totais da Guatemala em 2012 (ou US \$ 39 milhões) e atingiram o pico em 2007 em US \$ 66 milhões. Tradução nossa. Mais detalhes no artigo de Enrique Dussel Peters, documento produzido em 2014 pela Comisión Económica para América Latina y el Caribe (CEPAL), México. Disponível em: https://repositorio.cepal.org/bitstream/handle/11362/37151/1/S1420668_es.pdf 
e Goya resgatam com seu Huipil de Toó, é o personagem Polo, um distinto ativista de ONG que promove a soberania da terra para aldeias maias locais em que essas mesmas terras estão sendo ameaçadas por interesses internacionais de mineração. Polo, claro, é o personagem que vai apontar no romance a "causa" de toda instabilidade social maia e, com suas ações ativistas, que também metaforizam a militância no país desde a década de 6o na Guatemala por demarcações de terra e proteção da cultura indígena - assim como também a inclusão dessa mesma cultura na participação política do país - vai desestabilizar as estruturas dominantes da política corrupta e do capital canadense que estão lucrando com os operações de exploração e exportação internacionais da mineração.

A causa de Polo, que lembra os desafios enfrentados pelo ativista guatemalteco Adolfo Mijangos ${ }^{6}$ na década de 1970, desafia diretamente a hegemonia econômica da oligarquia e perpetua o ativismo que tem raízes históricas profundas na Guatemala, e uma longa tradição de oposição aos interesses de mineração. Ao mesmo tempo, o trabalho de Polo, no romance, juntamente com os esforços da "Comissão Internacional contra a Impunidade na Guatemala”, começa a atrair a atenção do público e passa a exercer novas formas de pressão sobre a corrupção governamental que muitas vezes está ligada a interesses

\footnotetext{
${ }^{6}$ Durante o governo de Julio César Méndez Montenegro (1966-1970) foi discutida a possibilidade de cessão de minas de níquel em Izabal para uma empresa canandense e depois permitir que os executivos da mineradora praticamente reescrevessem a Lei de Mineração guatemalteca. O governo iniciou o projeto de concessão de quarenta anos para a exploração de níquel à empresa Mineração e Explorações de Izabal, S.A. (EXMIBAL), uma subsidiária da empresa canadense International Nickel Company (INCO). A concessão não foi feita durante o governo de Méndez Montenegro, mas assim que o general Carlos Arana Osorio iniciou sua gestão presidencial em Io de julho de 1970, reabriu o caso da EXMIBAL e começou a trabalhar para concluir o processo de concessão de exploração da área demarcada na Guatemala. No entanto, muitos setores sociais se opuseram, argumentando que seria muito oneroso para o país. Um dos principais opositores foi a Comissão criada pela Universidade de San Carlos para discutir o assunto; entre os membros da comissão estava Adolfo Mijangos López, então deputado do Congresso e respeitado intelectual guatemalteco. Os outros dois membros da comissão que investigavam a EXMIBAL foram mortos a tiros: o professor Julio Camey Herrera e seu colega, Alfonso Bauer Paiz; Os membros da comissão se opuseram fortemente às condições da concessão proposta pelo Governo à EXMIBAL; Mijangos López foi morto por estranhos quando saía de seu escritório na $4^{\underline{a}}$ Avenida na Zona I da Cidade da Guatemala em 1971. Em 8 de maio de 1971, o governo de Arana Osorio finalmente concedeu a concessão à EXMIBAL cobrindo 385 quilômetros quadrados de área em El Estor, com um investimento inicial de US\$ 228 milhões. A mina, construída nas Montanhas Indígenas Q'eqchi, incluía um complexo residencial de 700 casas, numerosos escritórios, um hospital, um pequeno centro comercial, escola, um campo de golfe e uma grande área de processamento industrial. No ano seguinte, apesar das ameaças do governo de Carlos Arana Osorio, os estudantes fizeram uma homenagem a Mijangos López com sérias acusações contra o governo e os supostos mandantes do crime.
} 
de mineração que ameaçam a soberania das aldeias maias. Nas palavras do narrador de $E l$ país de Toó, é mais fácil vislumbrar este personagem:

A los cincuenta y cinco años Polo Yrrarraga era un hombre de cuerpo redondo, cara y cabeza redondas, ojos achinados y orejas de tazón. Ya no tenia pelo en la cabeza, pero se había dejado crecer el bigote y la barba, blanca y abundante. Algo de Padre Pío había en él, decían sus amigos. [...] Ahora mismo estaba sentado en un pequeño estudio de televisión del Canal Maya, hablando acerca del triunfo de las marchas multitudinarias qe él había ayudado a organizar, y que habían resultado en la destitución de un presidente en funciones (y exgeneral), de su vicepresidenta y de buena parte de su gabinete. [...] Bajaron al primer piso, y en la calle se encontraron con una rosca de periodistas y fotógrafos.

Ni modo - dijo Polo.

Queremos saber cómo piensa poner este pisto al servicio de la sociedad - le lanzó un periodista de pelo hirsuto y cara lampiña.

¿No tiene miedo, ahora que se ha hecho rico, de que lo secuestren? - quería saber otro. [...] Siguió una discusión bizantina sobre el efecto de las redes sociales en los movimientos de izquierda del último siglo. (REY ROSA, 2018: 49-53)

Como pano de fundo, criando um cenário dessas circunstâncias políticas em oposição ao culto do sagrado e seus resquícios e ruínas conservados em Toó, a narrativa está impregnada de interdiscursos de opressão política, cerceamento à liberdade de expressão e de imprensa (Polo é ativista político e ambiental e vive cercado por amigos jornalistas que lidam o tempo todo com notícias de desparecimento de pessoas, violências contra opositores do sistema de corrupção do país em referência aos anos de governo militar na Guatemala). Nas palavras de Polo, podemos demonstrar:

Alguien podría marcar y conectar, en este Centro - decía Polo - , los puntos donde se cometieran los principales asesinatos políticos de nuestra historia urbana, como el de la maestra de escuela María Chinchilla (1944), en la Siesta Avenida y Diecisiete Calle; el de Adolfo Mijangos, legislador (1971), en la Cuarta Avenida y Noventa Calle; el del dirigente universitario Oliverio Castañeda (1978) en la Novena Calle entre Quinta y Sexta Avenidas; el de Myrna Mack, antropóloga (1990), en la Quinta Avenida y Dieciocho Calle, el del Obispo Gerardi (1998), en la Sexta Avenida y Segunda Calle... para ilustración de los jóvenes e los turistas. (REY ROSA, 2018:55)

E, nas páginas seguintes, nos deparamos com imagens da memória de Polo neste mesmo sentido referencial - num estado catártico entre presente e passado recente - ao reunir acontecimentos sempre repetidos na realidade de seu país:

Sentado en un rincón a 1 mesa principal de Mi Cielito, mientras los demás hablaban ruidosamente o devoraban su comida, se vio a sí mismo como en un sueño diurno mirando aquel espacio vacío donde había estado la torre de la memoria. Y ahora los recuerdos parecían provenir de aquella cajá negra que guardaba los archivos de la Casa y de Neurálgica, filmados casi todos por él mismo a lo largo de tantos años. 
Los colores del mercado que veía desde su rincón (las flores a la venta en un puesto entre los comedores, los trajes de las mujeres mayas que atendían las mesas, la luz de neon sobre una carnicería en el fondo del corredor) se combinaron en el cerebro de Polo con los colores de un atardecer en un valle de altiplano. Pero la luz recordada iluminaba otra clase de carnecería y los colores eran los de los trajes de campesinos muertos durante un desalojo neoliberal, que fue el primero que documentó, hacia 1996, hacia los inicios de la supuesta paz local. Siguió el recuerdo de una ceremonia maya en Samayac, tierra de brujos, donde se le rinde culto a Maximón, supuesto protector de prostitutas y ladrones (que no hay que confundir con San Simón, el de los anticuarios). Prolongadas tomas de una manifestación de colectores kekchí de café o de cardamomo en Alta Verapaz. [...] Discursos políticos, de militares, de disidentes. La cara de Aldo muerto al timón de su carro, atravesado en la acera de la calle frente a su casa, a la vista de su esposa y de su hija y la sirvienta, pensó Polo. (REY ROSA, 2018:72)

Além dessas imagens reiteradamente mostradas em muitas das cenas da narrativa resgatando a luta das comunidades civis e indígenas em oposição ao progresso neoliberal há um personagem chave neste texto de Rey Rosa que ilustra todo o poder corrupto existente na vida política da Guatemala correndo sua origem, cultura, seu povo: Dom Emílio Carrión. Este personagem, muitas vezes referenciado no texto como “El Viejo" é um empresário com um passado sombrio cheio de mistério desde o início da narrativa. Alguém com muito poder político, financeiro e pertencente a uma espécie de sociedade secreta que aparece de forma mais imperiosa nos capítulos iniciais do texto para, progressivamente, ir sumindo à medida que "el viejo" é investigado e perseguido pela polícia anticorrupção, pela imprensa de Polo e pela Comissão Contra a Impunidade.

Nesses momentos nos deparamos com Dom Emílio buscando salvar-se de ser capturado, desenterrando riquezas e desfazendo amizades de conveniência política para traçar sua fuga. Rey Rosa nos mostra exatamente aqueles acontecimentos assistidos no dia a dia da realidade dos países da América Latina mostrados todas as noites pelos telejornais: o desvio e a lavagem de dinheiro ilícito, os grandes acúmulos de riquezas e bens pelos acusados de corrupção, facilidade de fugas, rotas de perseguição, investigação criminal e o papel da imprensa. Dom Emílio Carrión, el viejo, é quem representa toda essa problemática da Guatemala contemporânea:

De nuevo al volante del Audi, don Emilio encendió su celular. Había varios mensajes urgentes en el buzón. El primero de Frederico, su colega anticuario y amigo de correrías: Estoy con el telele, querido. Hoy creo que sí. Plan C, all the way! El otro, de uno de sus abogados, pero desde un número desconocido: Pelátelas, manín.

Mandar mensaje de texto a Carlos - le dijo a su teléfono inteligente, conectado al audio del auto.

En la casa mañana, que es mi santo, a las diez - dictó. 
Por el caso de corrupción masiva en el que estaba involucrado como operador y contacto entre funcionarios del gobierno y empresarios, tarde o temprano, le había dicho su abogado, lo iban a citar.

La casa de La Sacristía había sido allanada hacía una semana, y desde entonces don Emilio había estado ocultándose. Hablaba con la muchacha que la atendía, una joven estudiante de historia del arte, especializada en el barroco colonial, pero, urgencias aparte él no prefería pasar por allí. No había girado todavía, que él supiera, una orden de captura en su contra; era solo cuestión de tiempo. No había suficientes policías para tantos implicados, pensó. Pero ya se sentía como el zorro que oye, a lo lejos, el ladrido de los perros. Un amigo griego establecido en el país desde hacía más diez años le ofrecía (Pame volta) un vuelo en helicóptero. Pero ¿̇adónde?, se preguntaba. [...] Destino: el lago de Atitlán, donde Don Emílio tenía, cerca de San Pedro, un pequeño chalet. Aterrizarían en la cancha de futbol del pueblo, como era la costumbre. Su amigo entendería: alguien de la fiscalía iba a leer tarde o temprano ese mensaje. Pero él pediría al piloto que lo llevara a su casa del puerto. Una tiburonera, propiedad de un narco-lanchero de toda su confianza ("Tiburón enamorado", le decían a él y así le puso él a su nave), lo recogería en la playa, y en menos de dos horas navegarían ya en aguas de El Salvador, fuera del alcance de los tentáculos de la dudosa y agonizante ley de la pequeña y trágica republica decorativa. (REY ROSA, 2018:16I-163)

Dom Emílio representa, desse modo, o verme de uma política apodrecida que corrói as estruturas mais frágeis da sociedade da Guatemala, que sustenta e arrefece uma estrutura ainda maior de corrupção, de interesses privados em detrimento de uma estrutura movediça do governo estatal sempre à mercê de ser subornado pelo capital estrangeiro e neoliberal. De certo modo, alegoriza práticas e sociedades afundadas no lema "salve-se quem puder" muito mais comuns do que deveríamos ver nos países de toda a América Latia sempre sujeita às imposições de políticas canibalistas de mera exploração e venda de suas próprias riquezas. Como vimos, el viejo é forçado a fugir do país, e deixa seu legado para seu único filho Jacobo que, assim como suas demais posses, é deixado para trás depois de ter ficado anos internado num hospital psiquiátrico seu mando.

Jacobo, nesse sentido, pode ser pensado como alegoria contemporânea a realidade das sociedades menos favorecidas e marginalizadas da América Latina como um todo... de sofrimento e intimidação, de opressão, de vítima de um poder autoritário sob disfarce de um poder cuidador que nunca cuida, só flagela, persegue e aprisiona seus dominados para os fazer calar, desmemorizar, oprimir e fazê-los esquecer de quem eles são e, consequentemente, de suas raízes, suas origens e seu povo. Esse personagem funciona também como uma sombra: sabemos que ele existe como parte dos integrantes do texto, mas está o tempo todo sem voz, preso, silenciado, oprimido para que o poderio de Dom Emílio não se perca e sua história e dupla vida não venham à tona. Nada mais ideal como 
representação desse tipo de poder opressor do que um hospital psiquiátrico, um sanatório, um hospício, que é onde Jacobo é aprisionado pelo próprio pai e torturado. Referência clara ao uso da instituição psiquiátrica para o encarceramento de presos políticos nas décadas de 1970/1980. A violência asilar e o uso da psiquiatria em práticas repressivas de governos totalitários foram comuns durante a Ditadura Militar como instrumentos de “organização social e higienização" que até pouco tempo funcionaram para coação e repressão no regime totalitário.

$\mathrm{Na}$ ditadura militar do Brasil, por exemplo, a loucura era associada a qualquer desvio de comportamento aparente, resultando em muitos internamentos em hospícios e clínicas psiquiátricas sem que para isto houvesse necessidade. Qualquer pessoa que se desviasse das regras impostas pelos militares certamente seria conduzida para presídios ou hospícios. A "loucura" se tornou uma eficaz forma de controle, submetendo pessoas saudáveis do ponto de vista da psiquiatria convencional à internações com ingestão de remédios controlados e choques elétricos. Jacobito, nos poucos capítulos dedicados a ele somos surpreendidos ao ver seu pai e seu psiquiatra, Dr. Loyola, relatando sua condição mental:

Aquel sábado don Emilio y el doctor Loyola llegaron al mismo tiempo, pasaron las talanqueras entre la bruma uno tras otro, don Emilio en su Audi y el doctor en una Cherokee verde, y estacionaron uno junto al otro. [...] Jacobito nos ha dado un par de sorpresas - dijo luego el doctor, sin volverse a mirar al otro. La bruma se alzaba rápidamente y el sol, que apareció frente a ellos, los encandiló. [...] ¿Cómo, una sorpresa? $\mathrm{Su}$ retaso no es real. O, más bien, es solo un retraso expresivo, y muy parcial... Creemos que ha estado fingiendo desde hace algún tiempo.

No entiendo.

La apnea, la hipoxia, le dañó una zona del córtex y afecto su capacidad de habla. No camina ni se mueve como la gente normal a causa del mismo daño, eso lo sabemos. Pero es todo. Conservó su capacidad para entender. Entiende más de lo que yo pensaba. Mucho más.

¿Y?

El doctor soltó una risita que a su compañero le pareció siniestra.

Pues se ha ido enterando de todo, o caso. ¿Vos sabías que su nana lo visita cada quince o así? Ella le ha echado una mano. Y ella también se ha ido enterando por cierto.

No entiendo.

Tu hijo, Emílio, es tan listo como vos, si no más.

No sé de qué estás me hablando.

Durante todos estos años. ¿Ocho? Ha ido tomando la película. Tal vez no lo sabe todo dijo el doctor - Pero sabe más de lo que a vos y a mí nos conviene.

Sigo sin entender.

Mira. No tenemos tiempo. Voy a comenzar por lo más desagradable. Tienes que saber que tu hijo no puede verte.

¿Cómo? 
Como cualquiera adolescente. Pero peor. Y no le falta razón, diría yo, se me pongo en su lugar. Sueña con tu muerte. [...] Es posible que no lo volvamos a ver. [...] Yo por lo menos - siguió el doctor - me voy a largar pronto. [...]

¿Vas a explicarme de qué me estás hablando?

De todo Emilio. Para esto te cité, cerote.

Soy todo oídos.

Jacobo ya tiene más de quince. Yo ya no podré tenerlo en Los Cipreses, si él se quiere ir. Así es el reglamento. Y querrá irse, sí.

Don Emilio comenzaba a entender.

[...]

¿Cómo puede ser eso? - preguntó

¿Cómo puede ser qué?

Que su coco funcione. Me habías dicho que nada de nada.

A veces - dijo el doctor, dirigiendo la vista a un punto en la distancia hacia donde estaba el volcán de Agua - esas cosas suceden. (REY ROSA, 2018:155-158)

Jacobo ainda lança luz adicional sobre a decadência regressiva das estruturas econômicas e sociais que impedem o avanço do país em direção a uma sociedade mais igualitária. Em sua essência, a evolução de Jacobo é resultado da orientação espiritual e política oferecida pela mão carinhosa de Dona Matilde, sua nana. Matilde se liga a ele desde bebê e o tem como um verdadeiro filho. Não o abandona e sempre supervisiona sua estadia no hospital psiquiátrico. É ela também que facilita sua recuperação de um comprometimento cognitivo, primeiro através dela mesma, introduzindo nos quitutes que o presenteava cogumelos alucinógenos usados pelo povo maia como remédio - Ixtantlalok - e, mais tarde, através de suas explicações sobre a chegada e a queda do presidente do país, ironicamente chamado no texto de "El Futuro". Enquanto a recuperação dos bens de Jacobo é facilitada por Matilde, ela também aumenta sua consciência sobre as duras realidades de seu país e as atividades ilícitas de seu pai Emílio. O afastamento gradual de Jacobo e o distanciamento de seu pai vêm como resultado dessa tomada de consciência (uma "iluminação" propiciada pelas origens de seu povo) das atividades inescrupulosas de seu pai que envolvem corrupção e concubinato com o presidente preso. Essa separação de pai (como aquele que representa o lado escuro e podre da história) e filho (como aquele que traz redenção e esperança para o país), juntamente com Matilde (aquela que guarda a origem de seu povo e mantem seguro consigo o caminho para a igualdade de seu país, ou seja, a preservação da origem, das raízes e da história de seu povo), está por trás das forças primárias de redenção e de resgate da história de um país que necessita ser sempre preservado e revisitado para pensar o futuro e qualquer ideia de progresso. 
A tentativa de assassinato de Polo a mando de Dom Emilio e sua fuga do país são componentes fundamentais deste conflito que representam a atualidade de corrupção e impunidade não apenas na Guatemala, como em todos os países da América Latina. Junto a todos esses fatores, aparece outro personagem importante enquanto representação da marginalização da sociedade e como fruto dessas estruturas atuantes de corrupção. El Cobra, um órfão de El Salvador cujas alianças com Dom Emilio são sombrias até o fim do texto, é mais um personagem-chave devido à sua ligação com os centros de poder e a oposição. Trata-se de um dos personagens mais emblemático de El país de Toó já que traz à tona a forma como diversos setores da população latina são facilmente cooptados e atraídos para as redes de corrupção, crime organizado e tráfico de drogas tendo como mola propulsora a pobreza e a marginalidade.

As reformulações e transformações políticas que os personagens do El país de Toó vivenciam são corolários que ressaltam o tema predominante da necessária e substantiva reforma. Considerando que as instituições ladinos de poder histórico na Cidade da Guatemala são retratadas como decadentes e em uma espiral descendente, o texto de Rey Rosa também revela o surgimento de um espaço alternativo e radicalmente diferente que poderia servir como um roteiro para mudanças substantivas na Guatemala. Nas últimas seções do romance, o motorista de Don Emílio, El Cobra, consegue a redenção através de sua solidariedade com Dona Matilde, Toó e os povos maias em uma região dos estados remotos de Huehuetenango e San Marcos. Essas regiões são retratadas como espaços alternativos dentro da nação da Guatemala, e provocam o título do romance, "El país de Toó". Juntamente com seu próprio filho, Jacobo, e outros ativistas maias, El Cobra se integra habilmente a este território nascente e autônomo e aceita plenamente a integração maia com um novo respeito pelas terras indígenas e de interesses predatórios da mineração internacional que estão cada vez mais avançadas e promovidas pela corrupção neoliberal na capital. Em essência, Jacobo, El Cobra, Dona Matilde e Goya, uma jovem maia que se torna advogada, Rey Rosa cria um espaço-narrativo com personagens que exigem mudanças substantivas e positivas para a frágil república. Seus esforços apontam para um espaço utópico que só pode emergir através da compreensão intergeracional e étnica pautadas no 
reconhecimento final do povo maia em relação às decisões sobre o uso da terra em seus territórios ancestrais.

$\mathrm{Na}$ multiplicidade de sentidos que esse processo de alegorização produz em El país de Toó, é lícito ressaltar as palavras de Benjamin quando diz que na subjetividade do alegorista, onde "cada personagem, cada coisa, cada relação pode significar qualquer outra coisa" (BENJAMIN, 2013: I86), não vemos a apenas a arbitrariedade da expressão linguística, mas sua antinomia, a expressão da convenção sobre um mundo profano "em que o pormenor não é assim tão importante" (BENJAMIN, 2013:186) porque sozinho não revela-se a si próprio e nem relaciona-se com a história, tanto no que diz respeito a história mesma quanto aos objetos tomados como alegoria, já que trata-se, genuinamente, de um mundo salvífico em ruínas em que "a história não se revela como processo de vida eterna, mas antes como progredir de um inevitável declínio" (BENJAMIN, 2013:I89); um mundo histórico em que "aquela natureza que recebe a impressão da imagem do processo histórico é a natureza caída" (BENJAMIN, 2013: 191). Nenhuma imagem revela melhor a transitoriedade barroca da história do que uma caveira: "a história, com tudo aquilo que desde o início tem em si de extemporâneo, de sofrimento, de malogro, ganha expressão na imagem de um rosto, melhor de uma caveira" (BENJAMIN, 2013: 176). E a caveira, no caso desse texto de Rey Rosa, El país de Toó, parece ser a própria Guatemala contemporânea.

\section{REFERENCIAS BIBLIOGRÁFICAS}

BENJAMIN, Walter. Origem do drama trágico alemão. Trad. João Barrento. Belo Horizonte: Ed. Autêntica, 2013.

CARMACK, R.M., Harvest of Violence: The Maya Indians and the Guatemalan Crisis. Norman and London: University of Oklahoma Press. ed.I988

LOVELL, W.G. Conquest and Survival in Colonial Guatemala: A Historical Geography of the Cuchumatàn Highlands, I500-I821. Kingston and Montreal: McGill-Queen's University Press. 1985a

$1985 \mathrm{~b}$

From Conquest to Counter-Insurgency. Cultural Survival Quarterly 9(2):46-49. 
Surviving Conquest: The Maya of Guatemala in Historical Perspective. Latin American Research Review 23(2): 25-57. 1988

PAYERAS, M. Days of the Jungle: The Testimony of a Guatemalan Guerrillero, 1972-1983. New York: Monthly Review Press. 1976 